\title{
Colon cancer in the older population
}

\author{
Jakub Kenig \\ Department of General, Gastrointestinal, Oncologic Surgery and Transplantology, I Chair of General Surgery, \\ Jagiellonian University Medical College, Krakow, Poland
}

Fifty percent of new diagnoses of colorectal cancer are made in patients aged over 70 years, and 25\% are aged 80 years or over. Older patients tend to have locally advanced colon cancer, with negative lymph nodes and without distant metastasis. Frequently the colon cancer is located on the right side. There is still a belief that older patients can not manage curative treatment regimens. This is based on the results of older studies showing higher rates of short-term morbidity and mortality. At present, we are observing significant improvements in the outcomes of older patients with colon cancer in high volume centers. This could be due to better preoperative staging, increased use of minimally invasive techniques, better anesthesiology and perioperative care, awareness of complications, expertise and high-volume care. A standardized pre-operative diagnostic approach, individualized surgical technique selection and tailored postoperative care are essential for the successful treatment of older patients. Furthermore, counseling and shared decision-making should be based on modern insights in surgical outcomes rather than outdated data.

Key words: older oncologic patients, elderly, colon cancer, frailty

As the population aged 65 years and more increases worldwide and about $50 \%$ of all cancers occur in this group, $70 \%$ of them will die as result [1]. The third most common neoplasm worldwide is colorectal cancer (CRC) and its global incidence also continues to increase. 50\% of new diagnoses of CRC are made in patients aged over 70 years, and 25\% are aged over 80 years $[2,3]$. Therefore, the problem of CRC in older patient is very topical and it will gain even more importance over time.

\section{Characteristics of colon cancer in older patients}

Among older patients, more women than men develop colon cancer due to their longer life expectancy. The incidence of right-sided colon cancer increases with age. Older patients tend to have locally advanced colon cancer. The frequency, however, of lymph nodes and distant metastasis is lower com- pared to younger patients. Furthermore, more often, the CRC is well differentiated and less often the cells mucinousmobile or signet ring $[4,5]$.

\section{Preoperative assessment and treatment decisions}

As was mentioned before, the population of older patients is very heterogeneous with regard to co-morbidity, physical reserves, cognitive function and social support. The current routine pre-operative assessments also cannot adequately identify patients at risk. Therefore, the Comprehensive Geriatric Assessment (CGA) was introduced and should be performed before the beginning of treatment. The CGA helps to determine the primary status of the older patient, to diagnose frailty syndrome and to identify how to optimize the patient's condition before surgery. Surgery is one of the

\section{How to cite:}

Kenig J. Colon cancer in the older population. NOWOTWORY J Oncol 2021; 71: 119-121. 
primary triggers for disability in older patients. In this age group, it is more important to be mobile independent than to prolong life.

This is particularly true in patients with frailty syndrome, or decreased physiological reserves, which arise from cumulative deficits in several physiological systems and result in a diminished resistance to stressors. Therefore, a standardized pre-operative diagnostic approach, individualized surgical technique selection and tailored postoperative care are essential for successful treatment of older patients. This concept is also in agreement with the definition of health proposed by the World Health Organization; it is not a lack of disease or ailment but rather a state of well-being that encompasses physical, mental and social welfare. It is pivotal to preserve a patient's functional status and independence whilst at the same time minimizing the morbidity and mortality risks that they might be exposed to [6-8].

In general, based on the CGA, we can differentiate three groups of older patients:

1. Fit: patients without any deficits in CGA domains and less than 80 years. In this group standard oncologic treatment can be offered and the postoperative outcomes are comparable with young patients.

2. Pre-frail: patients with one deficit in the CGA domains or who are more than 80 years old. In these patients, prerehabilitation should be recommended before surgical treatment with standard intention.

3. Frail patients: patients with two or more impaired domains in the CGA or 80 years old with one deficit in the CGA. If these patients do not improve after prerehabilitaion, the tailored approach should be discussed in a geriatric multidisciplinary team meeting [9].

\section{Treatment of colon cancer in older patients}

Surgery plays a key role in the treatment of patients with CRC. In cases of stage I-III disease, surgery represents the main treatment option: most patients with stage I or II disease are treated by surgery alone; in the case of stage III, upfront surgical resection of the tumor along with adjuvant chemotherapy is the recommended treatment approach. A selected group of patients (potentially resectable metastases or symptomatic diseases: bleeding, obstruction) with stage IV disease may also take advantage of the surgical approach [10].

There is still a belief that older patients can not manage curative treatment regimens. This is based on the results of older studies that showed an association between chronological age and high rates of postoperative morbidity and mortality. At present, we can observe a significant improvement in the outcomes of older patients with colon cancer in high volume centers. Possible explanations could be better staging, increased use of minimally invasive techniques, better anesthesiology, better perioperative care, awareness of complications, expertise and high-volume care [10].
Therefore, colectomy with primary anastomosis is mostly well tolerated not only by the fitter older patient, but also by the pre-frail and not-severe frail patients when they are operated on by an experienced surgeon. There is no difference in the surgical complications rate between younger and older patients, with higher rate of medical complications. However, the mortality rate in the first six months postoperatively can be even 25\% among frail patients and functional recovery must be closely monitored. This is mainly due to body changes related to perioperative trauma and their influence on all aspects of well being, which in turn, further increase the risk of new complications [11].

Therefore, perfect surgery, in the case of older patients, is not the end of the battle for a better outcome, but instead just the beginning. Diagnosing frailty is not only a qualitative aspect but the severity of frailty can be quantified. However, its influence on perioperative decisions must be further explored (e.g. the importance of total mesocolic excision in frail patients, etc.)

In selected patients with early cancers, an endoscopic resection can be offered. An endoscopic submucosal dissection is ideal because of its en bloc resection. Although significantly less invasive than surgery, it still carries the risk of perforation and bleeding. Therefore, the procedures must be performed with caution $[12,13]$.

Minimal invasive colon cancer surgery is safe and has comparable oncological results as open surgery $[6,14]$. What is of paramount importance in older patients, is that minimal invasive surgical techniques evoke a less intensive immune response in comparison to open surgery, thus reducing the effects of perioperative trauma [16]. This could be an explanation for the improved recovery seen after minimal invasive surgery with less postoperative pain, shorter hospital admissions and less postoperative and cardiopulmonary complications [5, 15, $17,18]$ - a key element in the recovery of older patients [14-18].

\section{Conflict of interest: none declared}

\author{
Jakub Kenig \\ Jagiellonian University Medical College \\ I Chair of General Surgery \\ Department of General, Oncologic, Gastrointestinal Surgery and \\ Transplantology \\ ul. Jakubowskiego 2 \\ 30-688 Kraków, Poland \\ e-mail:jkenig@cm-uj.krakow.pl
}

Received and accepted: 7 Mar 2021

\section{References}

1. Edwards BK, Ward E, Kohler BA, et al. Annual report to the nation on the status of cancer, 1975-2006, featuring colorectal cancer trends and impact of interventions (risk factors, screening, and treatment) to reduce future rates. Cancer. 2010; 116(3): 544-573, doi: 10.1002/ cncr.24760, indexed in Pubmed: 19998273.

2. Balducci L. Studying cancer treatment in the elderly patient population. Cancer Control. 2014; 21(3): 215-220, doi: 10.1177/107327481402100306, indexed in Pubmed: 24955705. 
3. Siegel R, Naishadham D, Jemal A, et al. Cancer statistics, 2012. CA Cancer J Clin. 2012; 62(1): 10-29, doi: 10.3322/caac.20138, indexed in Pubmed: 22237781

4. Kotake $\mathrm{K}$, Asano M, Ozawa $\mathrm{H}$, et al. Tumour characteristics, treatment patterns and survival of patients aged 80 years or older with colorectal cancer. Colorectal Dis. 2015; 17(3): 205-215, doi: 10.1111/codi.12826, indexed in Pubmed: 25376705.

5. Siegel RL, Miller KD, Fedewa SA, et al. Colorectal cancer statistics, 2017. CA Cancer J Clin. 2017; 67(3): 177-193, doi: 10.3322/caac.21395, indexed in Pubmed: 28248415.

6. Xue DD, Cheng Y, Wu M, et al. Comprehensive geriatric assessment prediction of postoperative complications in gastrointestinal cancer patients: a meta-analysis. Clin Interv Aging. 2018; 13: 723-736, doi: 10.2147/CIA.S155409, indexed in Pubmed: 29731614.

7. Fariña-Castro R, Roque-Castellano C, Marchena-Gómez J, et al. Five-year survival after surgery in nonagenarian patients. Geriatr Gerontol Int. 2017; 17(12): 2389-2395, doi: 10.1111/ggi.13081, indexed in Pubmed: 28675571.

8. Simmonds PD, Best L, George S, et al. Surgery for colorectal cancer in elderly patients: a systematic review. The Lancet. 2000; 356(9234): 968-974, doi: 10.1016/s0140-6736(00)02713-6.

9. Grodzicki T, Kenig J. Problemy okołooperacyjne u osób w wieku podeszłym. PZWL Wydawnictwo Lekarskie, Warszawa 2018.

10. Chong RC, Ong MW, Tan KY. Managing elderly with colorectal cancer. J Gastrointest Oncol. 2019; 10(6): 1266-1273, doi: 10.21037/ jgo.2019.09.04, indexed in Pubmed: 31949947.

11. Aquina CT, Mohile SG, Tejani MA, et al. The impact of age on complications, survival, and cause of death following colon cancer surgery. Br J Cancer. 2017; 116(3): 389-397, doi: 10.1038/bjc.2016.421, indexed in Pubmed: 28056465.
12. Takahashi Y, Mizuno Kl, Takahashi K, et al. Long-term outcomes of colorectal endoscopic submucosal dissection in elderly patients. Int J Colorectal Dis. 2017; 32(4): 567-573, doi: 10.1007/s00384-016-2719-y, indexed in Pubmed: 27900464.

13. Takahashi Y, Mizuno Kl, Takahashi K, et al. Long-term outcomes of colorectal endoscopic submucosal dissection in elderly patients. Int J Colorectal Dis. 2017; 32(4): 567-573, doi: 10.1007/s00384-016-2719-y, indexed in Pubmed: 27900464.

14. Ngu JCY, Kuo LJ, Teo NZ. Minimally invasive surgery in the geriatric patient with colon cancer. J Gastrointest Oncol. 2020; 11(3): 540-544, doi: 10.21037/jgo.2020.02.02, indexed in Pubmed: 32655932.

15. Cone MM, Herzig DO, Diggs BS, et al. Dramatic decreases in mortality from laparoscopic colon resections based on data from the Nationwide Inpatient Sample. Arch Surg. 2011; 146(5): 594-599, doi: 10.1001/ archsurg.2011.79, indexed in Pubmed: 21576611.

16. Webb S, Rubinfeld I, Velanovich V, et al. Using National Surgical Quality Improvement Program (NSQIP) data for risk adjustment to compare Clavien 4 and 5 complications in open and laparoscopic colectomy. Surg Endosc. 2012; 26(3): 732-737, doi: 10.1007/s00464-011-1944-2, indexed in Pubmed: 22038161.

17. Stefanou AJ, Reickert CA, Velanovich V, et al. Laparoscopic colectomy significantly decreases length of stay compared with open operation. Surg Endosc. 2012; 26(1): 144-148, doi: 10.1007/s00464-011-1840-9, indexed in Pubmed: 21792714.

18. Ketelaers SHJ, Fahim M, Rutten HJT, et al. When and how should surgery be performed in senior colorectal cancer patients? Eur J Surg Oncol. 2020; 46(3): 326-332, doi: 10.1016/j.ejso.2020.01.007, indexed in Pubmed: 31955993. 